\title{
perifèria
}

Número 16, junio 2012

revistes.uab.cat/periferia - www.periferia.name

\section{Anàlisi d'una deriva agro-ecològica des de la Història i la Teoria Crítica en el Pensament Antropològic}

\author{
Autor: Damià Vinyet Soley ${ }^{1}$ \\ Universitat Autònoma de Barcelona \\ Co-autor: Pablo Domínguez Gregorio \\ Centre for Biocultural Diversity \\ School of Anthropology and Conservation - University of Kent
}

\begin{abstract}
Resum
Basant-se en una discussió existent des de molt temps ençà en les ciències socials, universalisme vs relativisme, el present article exposa els efectes que ha generat un tipus d'orientació universalista (filosofia de la Revolució Verda) respecte la producció d'aliments a la comarca d'Osona (Catalunya central). Concretament, s'analitzen la deriva històrica i les diferents conseqüències econòmiques, socials i ambientals que ha causat el fet de prioritzar al sector porcí en la producció alimentària d'aquesta comarca dins d'una concepció d'integració al mercat global. Així, es contempla el resultat actual d'un procés que es va iniciar als anys 80 , quan aquesta producció es va intensificar radicalment, es va desvincular del territori i les grans empreses es van acabar fen amb una àmplia part del control. Concloem que un universalisme extrem i etnocèntric occidental aplicat a la producció d'aliments, ha generat desequilibris socials, problemes ambientals i ha polaritzat l'economia productiva de la zona.
\end{abstract}

Paraules clau: Teoria critica del pensament antropològic, universalisme vs relativisme, producció alimentaria, revolució verda, porcí, Catalunya, Osona.

\begin{abstract}
Based on a long time existing discussion in the social sciences, universalism vs. relativism, this article presents the effects that this kind of universalist orientation (green revolution philosophy) has created concerning food production in Osona's region (central Catalonia). More precisely, this study analyzes the historical derive and the different economic, social and environmental consequences that the prioritization of the pig sector caused in this region within a conceptual framework of global market integration. Thus, we observe the present results of a process that took off in the 1980's, when local pig production was radically intensified

\footnotetext{
1 Enviar correspondencia a: Damià Vinyet Soley, damiavs@hotmail.com ; Pablo Domínguez Gregório, P.Dominguez@kent.ac.uk
} 


\section{perifèria}

Número 16, junio 2012

revistes.uab.cat/periferia - www.periferia.name

increasingly dissociated from the territory and large corporations have come to exercise a great deal of its control. We conclude that an extreme and ethnocentric western universalism applied to food production, has generated social inequality, environmental problems and has polarized the productive economy of the area.

Keywords: Critical theory of anthropological thought, universalism vs. relativism, food production, green revolution, pigs, Catalonia, Osona.

\section{Introducció}

Com ja s'ha vist en diversos estudis, els models homogeneïtzants de producció d'aliments dins d'una economia globalitzada, impulsada entre altres coses per un suposat progrés universal i llavors principalment etnocentrat en l'Occident, com es veurà més extensament en els apartats de Context i Tesi, ha afavorit la creació de molts desequilibris socio-ecològics arreu del món. Així, el monocultiu de cacau, arròs, cafè, cotó, sucre o cautxú en els diferents continents, ha creat una dependència dels productors cap un mercat mundial (de fet, generalment poc estable com s'ha vist moltes vegades en l'últim segle i especialment amb la actual crisi), el qual al mateix temps, ha fet perdre gran part de la seva autosuficiència $i$ sostenibilitat ambiental (Duch 2010; Moore et al. 2008).

Aquesta situació s'ha esdevingut principalment pel fet de produir en termes purament de mercat (food commoditization), on s'ha deixat de banda la producció d'aliments bàsics per la subsistència de la població local i la seva relació amb els límits dels ecosistemes locals. Així, cada cop més arreu del món, es produeix més en monocultiu per obtenir uns beneficis a curt plaç però que, en qualsevol cas, no ha demostrat la seva capacitat per fer front a crisis majors de llarg recorregut. És el cas, entre molts, de les pèrdues milionàries de l'agricultura a Indonèsia que, en la seva majoria, havia adoptat des de feia dos dècades la Revolució Verda (conjunt d'avenços accelerats des dels anys 50 relatius a la tecnologia agronòmica, que ha set interpretat com un progrés universal pel conjunt de la humanitat), i que al 1997, amb la crisis econòmica del sud-est asiàtic i l'arribada de El Niño va sucumbir estrepitosament, mentre que les poblacions indígenes, llargament adaptades a les fluctuacions del clima i de l'ambient, que sempre havien mantingut una gran diversitat en varietats de cultiu, finalment van demostrar ser més durables i resistents a pesar de ser menys productives a curt plaç (Ellen 2007). Efectes com 


\section{perifèria}

Número 16, junio 2012

revistes.uab.cat/periferia - www.periferia.name

aquests, són sota la nostra perspectiva, els que demostren l'impossibilitat d'un desenvolupament veritablement sostenible des d'una concepció universalista homogeneïtzant.

En aquest context, el cas de la producció d'aliments a la comarca d'Osona, una comarca del centre de Catalunya englobada a la província de Barcelona, no es una excepció. L'objectiu del present treball és doncs, constatar els efectes que pot arribar a generar una visió universalista la qual homogeneïtzi l'alimentació, en la deriva agro-ecològica osonenca dels últims 30 anys, des d'un punt de vista original: la Teoria Crítica del Pensament Antropològic. Des dels anys 80, en aquesta comarca s'ha intensificat enormement la producció de porc, és a dir, s'ha orientat la producció alimentària de tota la comarca cap a aquest tipus de producció. Al 2010, aquesta producció ja representava el 52\% del Valor Afegit Brut (VAB) del sector primari d'Osona². A més, al voltant d'aquesta especialització ramadera s'ha creat un important sector d'agrobusiness i agroalimentari, fet que ha generat un autèntic clúster ramader a la comarca, on qualsevol aspecte que afecti o pugui afectar a l'estructura productiva ramadera tindrà un impacte més gran a nivell econòmic, social o ecològic (Garcia 2006). Degut aquest efecte estructural, volem contrastar un model productiu diversificat, igualitari i relatiu a la zona. Tot això amb la finalitat de constatar les repercussions socials $i$ individuals que genera un tipus de model universalista en oposició d'un altre model més relativista en quan a la producció agronòmica es refereix, i dient agronòmica es contempla també els aspectes socioculturals implícits en aquesta.

La hipòtesi principal a seguir és que un pensament neoliberal universalista de la producció d'aliments que pretén ser el mètode pel desenvolupament local genera de fet, desequilibris socials, econòmics i ambientals. A Osona el sector porcí ha esdevingut I'eix principal de producció de la comarca degut a l'especialització del propi sector i el desenvolupament d'una macroindústria càrnia que ha adoptat els modes de producció d'una filosofia de quantitat sense contextualització local. Al 1982, hi havia 2.287 explotacions porcines amb un total de 277.786 caps $^{3}$, en canvi

\footnotetext{
${ }^{2}$ Dossier Comarcal d'Osona 2010.

${ }^{3}$ Dades d'Indescat.
} 


\section{perifèria}

Número 16, junio 2012

revistes.uab.cat/periferia - www.periferia.name

al 2010 les explotacions havien baixat fins a 914 tot i que el cens total era de $943.247^{4}$. Aquest fet ha enfortit i generat més guanys a les grans empreses que controlen la producció, transformació i distribució, mentre que ha deixat fora els petits productors. A part, ha provocat una contaminació per nitrats de les aigües subterrànies, fet que impossibilita el seu aprofitament humà ${ }^{5}$. Aquest és un bon exemple de que creixement no implica obligatòriament desenvolupament.

La metodologia s'ha basat en una observació participant del procés a Osona entre els anys 2003 y 2011 i la participació en sessions de discussió sobre el debat universalisme/relativisme efectuades entre Abril i Juny del 2011 dins I'assignatura Teoria Crítica de la Ilicenciatura d'Antropologia Social i Cultural de la Universitat Autònoma de Barcelona. En aquests seminaris es varen analitzar textos de diferents autors, una part dels quals, es presenten en l'apartat de Tesis i Anti Tesis. Pel context científic i social o pel cas empíric, m’he basat en una investigació i lectura àmplia de bibliografia sobre el tema en qüestió. A més, durant l'escriptura del present treball, he pogut realitzar unes visites als centres de producció i un recull d'informacions del sector per assolir-ne un major coneixement.

\section{Context científic i social}

La discussió entre relativisme i universalisme ha sigut un tema recurrent a tota la història de la filosofia i de les ciències socials en general. Històricament, aquesta discussió s'ha centrat principalment en l'ètica i la moral. Així, des del segle V a.C. ja es té constància d'aquesta diferent visió amb les divergències de pensament entre els sofistes i el de Sòcrates o Plató. Aquest últim, per exemple, a partir del seu raonament del món de les idees, apunta per una ètica de tall racionalista i universalista on els valors morals són objectius, es poden conèixer, són eterns i immutables. Els sofistes en canvi, van ser els "primers" en aportar la idea del subjectivisme on cada individu i cultura havia de viure segons les seves pròpies conviccions.

\footnotetext{
${ }^{4}$ Dossier Comarcal d'Osona 2010.

${ }^{5}$ Molts pous de la Plana de Vic els nivells de nitrats superen els $100 \mathrm{mg} / \mathrm{l}$, fet que supera els $50 \mathrm{mg} / \mathrm{l}$ que permet la legislació present (Pla Estratègic Osona XXI).
} 


\section{perifèria}

Número 16, junio 2012

revistes.uab.cat/periferia - www.periferia.name

A partir d'aquestes primeres discussions, els principals filòsofs s'han anat decantant per una proposta, I'altra o variants intermèdies d'aquests dos extrems. Així, per exemple, filòsofs com Kant, creien que I'objectiu final és arribar a una veritat universal i objectiva (Reboul 1993:73). Avui dia encara hi ha molts intel-lectuals de reconegut prestigi qui defensen aquest objectiu, com ara Habermas que a partir del diàleg i la comunicació, creu que es pot arribar a un consens que s'ajustaria a la dimensió subjectiva de l'ètica i moral, tot legitimant el bé comú (Habermas 1999). Aquest tipus de concepció, fundamentalment sorgida en primer lloc del racionalisme grec, de l'universalisme cristià després i reformulat i rellançat amb força per la Il-lustració, és la que va permetre la Declaració Universal del Drets Humans per la ONU al 1948. Per altra banda, seguint certes actituds dels sofistes, filòsofs com Nietzsche (Reboul 1993) o Hume neguen una visió universalista dels valors morals i creuen que aquests valors són una construcció occidental o al menys pròpia a certes cultures, sense existència objectiva.

Dins la disciplina de l'antropologia ha estat molt present aquesta dicotomia. Així, la teoria evolucionista, basada en el positivisme i en la raó provinents de la il-lustració, proposa un universalisme cultural, econòmic i inclús psíquic de la humanitat. Aquesta proposta concep la història de la humanitat com un progrés des de formes menys evolucionades o racionals (els anomenats "primitius o salvatges") a formes més evolucionades o racionals (visió etno-céntrica). Aquest paradigma canvia, amb una resposta crítica a l'evolucionisme, amb l'entrada del particularisme històric de Franz Boas, on s'apuntava a un relativisme cultural. Aquesta resposta va tenir continuïtat amb l'estudi d'àrees culturals efectuades pels seus deixebles com Kroeber, Benedict o Mead (Lombard 1994). A partir d'aquí, i sobretot després de la Segona Guerra Mundial, les diferents escoles i autors s'han posicionat per una banda, per l'altra o per algun punt entremig, com ho veurem a l'apartat de Tesis.

Aquest debat propicia una forma de veure el món diferent $\mathrm{i}$ unes conseqüències pràctiques distintes segons la posició que un adopti. Un exemple seria la diferent concepció del món i de les cultures que proposen diferents models de producció d'aliments. Per una banda, la macro-indústria alimentària massiva del món globalitzat i el lliure mercat com a forma d'universalisme, ja que es presenta i s'imposa una única forma de producció i distribució d’aliments, com l'únic objectiu 


\section{perifèria}

Número 16, junio 2012

revistes.uab.cat/periferia - www.periferia.name

final possible de la humanitat, per igual a tots els territoris del món. Per altra banda, el relativisme en la proposta de producció i consum local on es potencia el tipus de producció i distribució d'aliments pròpia, adaptada al medi i conseqüent amb el seu context social.

El sorgiment teoric-pràctic d'aquestes propostes de producció alimentària en termes quantitatius són, en part, sorgides d'una mentalitat heretada de l'universalisme il-lustrat etnocèntric i la idea de que progrés tecnològic és igual a progrés humà. Fet que es recull pràcticament de manera literal en la Revolució Verda iniciada als anys 50 gràcies als avenços de la biotecnologia, i posada realment en marxa a partir del anys 70. En I'època de canvis després de la Segona Guerra Mundial, els Estats Units en surten reforçats i assoleixen una gran dominació mundial, excepte, és clar, dels països comunistes. Aquesta intervenció mundial es veu reflectida en el discurs del seu president Harry Truman qui, el 1949, reafirma I'hegemonia dels EEUU tot classificant el món en termes de producció i renda econòmica. Així, considerava el món dividit en dos tipus de països: els desenvolupats (entre els quals es trobaven ells) i els subdesenvolupats als quals s'havia "d'ajudar" per tal que assolissin l'estatus de "desenvolupats" (Gimeno 1999). Per Harry Truman, tots els pobles del món caminaven en la mateixa pista, uns ràpid, els altres més lents, però tots en la mateixa direcció, amb els països del nord, particularment els EEUU per davant. Es tracta doncs, d'una proposta universalista amb base evolucionista, però que de fet, era relativa a la seva pròpia cultura. Aquesta teoria i pràctica del desenvolupament deixa de tenir en compte la possibilitat de diferents models de desenvolupaments o diferents potencialitats latents $\mathrm{i}$ susceptibles que es puguin desenvolupar, per seguir un model únic, singular i fixat pels països i grups socials que lideren la cursa. Així el govern dels Estats Units, la seva indústria alimentària i fundacions com la Fundació Rockefeller o la Fundació Ford ${ }^{6}$, van estimular i potenciar un canvi de producció agrària al món en nom d'erradicar la fam mundial.

\footnotetext{
${ }^{6}$ La Fundació Rockefeller és una organització privada nord-americana creada a finals del segle XIX. Entre altres objectius hi figura el fet de finançar el desenvolupament agrícola pel subministrament d'aliments a tot el món. Al 1940, va iniciar una investigació en les llavors de blat de moro a Mèxic on, desprès de la selecció, es van crear uns híbrids que obtindrien uns resultats productius millors dels existents a Mèxic. Aquest fet va facilitar la cooperació de la Fundació Rockefeller amb els investigadors i autoritats de Mèxic (Martinez 2002).
} 


\section{perifèria}

Número 16, junio 2012

revistes.uab.cat/periferia - www.periferia.name

Aquest canvi de producció a nivell mundial consistia en incrementar la productivitat agrícola fent ús de varietats millorades genèticament de blat, blat de moro, arròs o ordi que es proporcionaven a aquestes nacions, tot deixant de banda les seves varietats locals i la seva autosuficiència interna. La forma de cultiu era en base a una sola espècie en un mateix i extens terreny durant tot l'any, és a dir, s'aplicava el monocultiu. Aquesta producció, a més, anava associada a grans quantitats d'energia, aigua, fertilitzants, pesticides, a més d'una tecnologia, maneig i organització laboral concreta i distinta. A part, en molts casos les llavors usades estan patentades i no és possible la seva reproducció per la pròxima sembra (Duch 2010). Així, al cap dels anys, les empreses transnacionals com Monsanto, Cargill, Carrefour, Nestlé, Syngenta o Archer Daniels Midland han arribat a exercir un control directe en la majoria de països sobre la comercialització d'aquests productes, els mercats de llavors, els agrotòxics, els fertilitzants, I'aigua, la genètica animal i, a més, sobre la seva terra productiva (Duch 2010).

Realment, aquesta estratègia va fer augmentar considerablement la producció mundial d'aliments, fins el punt de cobrir-ne les necessitats "teòriques". Per exemple el 1992, al món ja es produïen cereals suficients per proveir 3.500 calories diàries a cada esser humà del planeta ${ }^{7}$. A més, aquesta estimació no té en compte altres aliments com verdures, llegums, fruits secs, tubercles, fruites, peix o els productes de la ramaderia extensiva. Aquesta dada, actualment, encara és més aclaparadora. Per tant, la fita proposada dins la Revolució Verda ja fa anys que es va assolir. Així doncs, la pregunta a fer és: per què no s'ha acabat amb la fam mundial? La resposta sembla induïble, aquest no era l'objectiu real, o almenys se n'ha desviat substancialment. L'Índia, com a país exemple en què es va imposar un canvi de model productiu, al 1995 almenys 200 milions de persones patien fam. Tot i així, exportava blat i farina per valor de 625 milions de dòlars i arròs per valor de

La Fundació Ford va ser creada al 1936 per finançar programes que promouen la democràcia, redueixin la pobresa i promoguin el desenvolupament humà. Així, juntament amb la Fundació Rockefeller, van introduir unes noves varietats de llavors d'alt rendiment a l'índia desenvolupades a Mèxic i Filipines, les quals anaven acompanyades de fertilitzants químics i major reg (Metcalf 2003).

${ }^{7}$ Calculat FAO, 1992 producción Yearbook, vol. 46 (Roma, FAO, 1993. dins Moore el al. 2005). 


\section{perifèria}

Número 16, junio 2012

revistes.uab.cat/periferia - www.periferia.name

1.300 milions de dòlars, dos aliments fonamentals en la dieta de la seva població ${ }^{\text {. }}$ Aquests aliments doncs, entren a formar part del mercat mundial, controlat per alguns dels mateixos que van potenciar aquest tipus de producció ${ }^{9}$.

Les crítiques a la Revolució Verda no van tardar a aparèixer. Aquestes crítiques es basaven en aspectes negatius que aquesta va comportar localment a pesar del seu objectiu universalista: I'exclusió social, la migració cap a les ciutats degut a la pèrdua de terres per part dels petits camperols, dependència del mercat mundial $i$ dels preus que aquest estableix degut a l'especulació, problemes a l'hora de l'emmagatzematge, excés de cost de les llavors i tecnologia complementària, la dependència tecnològica, la menor adaptació enfront dels cultius tradicionals o I'aparició de noves plagues. Així, aquesta crítica és des de diferents punts de vista: ecològic, econòmic, social i nutricional.

Com a resposta a aquesta política homogeneïtzadora de producció, apareix als anys 70 el concepte d'agro-ecologia que, posteriorment, el moviment internacional camperol Via Campesina va concretar amb la proposta de sobirania alimentària I'any 1996 i que avui sembla derivar cap a la permacultura. Així, aquestes propostes relativistes aposten pel dret dels usuaris del territori a determinar les filosofies i polítiques agrícoles i alimentàries que els afecten, a tenir dret i accés a la terra, als recursos naturals, a poder alimentar-se de forma sana i saludable amb aliments lliures de transgènics ${ }^{10}$, a protegir i a regular la producció i el comerç agrícola interior.

L'objectiu és doncs, debatir sobre el camí cap a un desenvolupament sostenible i la seguretat alimentària, a partir d'un cas a la Catalunya central, i des d'un punt de

${ }^{8}$ Calculat per FAO, 1996. Mapping Undenutrition: An Ongoing Process, (Roma, FAO, 1996. dins Moore et al. 2005).

${ }^{9}$ Grans multinacionals, entre elles empreses com Monsanto, Nestlé o Cargill són membres en varis grups industrials i comercials que exerceixen pressió mundial sobre les polítiques de comerç i de mercat establertes pel Banc Mundial (BM), el Fons Monetari Internacional (FMI)o la Organització Mundial del Comerç (OMC). Aquests grups de pressió són la Cambra de Comerç Internacional (CCI), La Taula Rodona d'Industrials Europeus (ERT), Consell d'EEUU pel Comerç Internacional (USCIB) o El Consell Industrials sobre Assumptes Nacionals (BNCI).(Balanyá 2002)

${ }^{10}$ Estudis de I'Acadèmia Americana de Medicina Ambiental sobre animals conclouen que existeix relació de causalitat entre el consum d'aliments transgènics i efectes adversos per la salut. (Duch 2010:96) 


\section{perifèria}

Número 16, junio 2012

revistes.uab.cat/periferia - www.periferia.name

vista de la Teoria Crítica en el Pensament Antropològic que mostri la capacitat de la nostra disciplina a aportar el seu gra particular al debat.

\section{Tesis i anti tesis del debat universalista}

En aquest apartat es repassaran de forma transversal les diferents concepcions presents en els conceptes d'universalisme i relativisme, com també els diferents gradients presents entre ambdós, a partir del plantejament antropològic de diferents autors i escoles.

- L'universalisme racista a partir de I'II·lustració

En un extrem, trobaríem una forma d'universalisme racista present en alguns autors de la Il-lustració o hereus de la mateixa. Entre els il/lustrats podríem mencionar el generat per Voltaire, Turgot o Condorcet. Per Voltaire, l'ètica no es troba subordinada a la història, la sociologia o la política ja que es tracta d'un àmbit inherent a la nostra pròpia naturalesa, per tant, l'ètica és universal. Tot i així, Voltaire sostenia que el grau de civilització dels individus de color era un resultat de la seva inferior intel-ligència:

"Si su comprensión no es de distinta naturaleza que la nuestra, sí que es por lo menos muy inferior. No son capaces de una verdadera aplicación o asociación de ideas y no aparecen formados ni para las ventajas ni para los abusos de la filosofia" (citat a Harris 1979:75).

Així, està en contra de la tesi del "bon salvatge" de Rousseau, el qual creu que és la societat, l'estat o la cultura la que perverteix i degenera la innocència primitiva de I'home, com és el cas dels "salvatges". Però aquesta defensa de l'unitat psíquica de la humanitat que fa Rousseau, explica encara la perfectibilitat de la societat amb la creença de la capacitat dels homes per millorar les seves formes de vida mitjançant l'exercici de la raó. Amb aquests dos autors es presenten dos models de consideració de l'altre en l'època il-lustrada: el "salvatge" endarrerit i inferior, que ha de progressar en la civilització, i el "bon salvatge", viva imatge dels valors i ideals perduts per Occident. En ambdós casos però, es denota la visió universalista 


\section{perifèria}

Número 16, junio 2012

revistes.uab.cat/periferia - www.periferia.name

de l'Il-lustració on es pressuposa la història humana com a progrés des de formes menys evolucionades o racionals a formes més evolucionades o racionals de la societat. Aquesta última societat ocupa la posició culminant en una escala jeràrquica de les societats, fet que li dóna el dret a "dominar" les altres.

\section{- L'universalisme moderat (o relativisme moderat) de Lévi-Strauss}

Per rebatre la teoria racista present en la societat occidental de principis del segle XX, Lévi-Strauss escriu Raza e Historia (1961). Cal tenir en compte que el determinisme racial estava molt extès encara, però basat fonamentalment en autors del segle XIX com Hegel, Comte o Gobineau. Així, Lévi-Strauss (1961) s'oposa a aquesta visió d'universalisme racista, enunciant que no hi ha cap evidència de diferència biològica-racial que determini el comportament social. Aquest comportament doncs, és degut a la cultura com ho demostra el fet que hi ha milers de cultures i només unes poques "races", i això si podem reconèixer la noció de raça com a vàlida. A més, moltes vegades hi ha més similituds culturals de grups racialment diferents que en grups racialment propers. De fet, Lévi-Strauss defensa una universalitat de l'espècie humana i d'una part fonamental del seu pensament, la ment binaria fruit d'aquesta universalitat biològica. Per tant, argumenta que un occidental i un "salvatge" usen els mateixos mecanismes interns per assolir el pensament tot i que es manifesten de formes diferents (Lévi-Strauss 1962:43-76).

La crítica a l'evolucionisme és que ha intentat suprimir la diversitat, i no és altra cosa que etnocentrisme. Lévi-Strauss (1961) anuncia que la diversitat cultural és un fet, que sempre serà en major o menor mesura, i que no hi ha cultures superiors sinó que totes evolucionen de forma diferent i cap a direccions diferents. El problema rau en la posició etnocèntrica des la qual es valora. A més, opina que no hi ha cap societat que es desenvolupi en soledat sinó degut a la interacció amb altres. Per això, creu que tota la civilització mundial va cap a una certa direcció (universalisme) però, aquesta, és un resultat de la interacció i contribució de les diferents direccions que presenta cada cultura (relativisme). 


\section{perifèria}

Número 16, junio 2012

revistes.uab.cat/periferia - www.periferia.name

- La visió universalista anti-relativista de Ernest Gellner

Gellner recull les diferents cosmovisions i propostes nombrades anteriorment per establir la seva teoria universalista. Així, es considera a si mateix com a fill de la Il-Iustració on defensa el positivisme, I'humanisme i la ciència amb pretensió objectiva. Estableix, en línia amb Lévi-Straus (1961), la universalitat del pensament humà i, a més, també defensa una metodologia universal de les ciències socials i de I'Antropologia per assolir el coneixement. Aquesta ciència "ha triunfado, de un modo u otro, sobre todos los demás, a juzgar por el criterio pragmático de la eficacia tecnológica, pero también de acuerdo con criterios tales como la precisión, la elaboración, la elegancia y la expansión sostenida y consensuada" (Gellner 1992:81). Gellner proposa la universalitat de la ciència, gràcies a la qual s'assoleix un coneixement objectivable que pot discernir la veritat, que "transcendeix la cultura i la moralitat" ja que està més enllà i fora de tota cultura (Gellner 1992:96) i ens aporta que "la existencia de un conocimiento amoral y transcultural es el hecho de nuestras vidas" (Gellner 1992:73). La ciència doncs, no és només l'aspecte cognitiu de les diferents cultures sinó que és "el coneixement en si" (Gellner 1992:103).

Per tant, Gellner afirma una universalitat cultural entre els humans basant-se en una zona comuna del pensament que opera dins un aparell cognitiu comú. Per ell, aquest aparell cognitiu comú és el resultat del punt d'interacció entre la cultura i la infraestructura. Així, dues societats poden diferenciar-se a nivell de la cultura i la infraestructura però mantindran un mínim comú universal, el que ell anomena aparell cognitiu comú. Gellner (1992) doncs, s'oposa al relativisme.

Després d'exposar les tesis de Gellner, crec pertinent dins aquest treball, reflexionar, ni que sigui una pinzellada, sobre "la universalitat d'una ciència objectivable que transcendeix a la cultura i a la moralitat". En la història de la antropologia, com en general de les ciències humanes, ha quedat constatat, per exemple amb el text de Stolcke (1993), el fet de que aquesta ciència ha estat sovint subjecte al poder o basat únicament a la visió occidental. Pel que respecte a les ciències naturals i tecnològiques, aquest fet no deixa de diferir. Així, I'establiment de la Revolució Verda, es va portar a terme reforçats en nom 


\section{perifèria}

Número 16, junio 2012

revistes.uab.cat/periferia - www.periferia.name

d'aquestes ciències considerades objectivables i veritables. Tanmateix, com intentaré exposar en aquest treball, les consideracions d'aquesta suposada veritat única no es poden declarar universals, sinó etnocèntriques.

\section{- L'anti-antirelativisme de Clifford Geertz}

Geertz, tot i que no proclama una defensa del relativisme, es mostra del tot contrari amb els defensors de I'antirrelativisme. Ara bé, Geertz (1996) a partir de la descripció densa, la interpretació de les interpretacions i la inscripció dels discursos socials, es decanta de fet, cap a un cert relativisme. Així, aquests indicis de relativisme que assumia Geertz (1996) era el refús de constants formals, evolutives i operatives que, en nom d'una raó universal, només suposen la superioritat etnocentrista de la civilització occidental sobre la resta de cultures. Per tant, també expressa la seva discrepància sobre el relativisme extrem ja que aquest, essent etnocèntric, podria arribar a causar les aberracions humanes com les que van arribar a causar el nazisme o el "comunisme" de Stalin.

Així doncs, Geertz (1996) critica l'antirrelativisme per la simplificació de la seva visó, la separació de l'estudi de la moral i cultura, on la primera es considera premeditadament natural i universal als essers humans degut a un etnocentrisme occidental i on qualsevol orientació diferent és considerada una desviació.

- L'articulació universalisme - relativisme de Tzvetan Todorov i Stanley J. Tambiah

Todorov (1988) exposa una solució a l'antítesi present entre universalisme i relativisme. Així, creu que l'evolució de la humanitat està dotada d'una certa direcció, amb un cert sentit històric. Tot i així, existeixen ritmes evolutius diferents i moviments en sentit contrari (tal i com exposa Lévi-Strauss amb la metàfora dels trens (Lévi-Strauss, 1996), amb un resultat innegable d'una evolució que privilegia certes formes culturals. Aquesta doncs, seria la basant universalista, mentre que el relativisme facilita un reconeixement acumulat d'altres cultures, l'augment del respecte cap a l'alteritat i la comprensió de les nostres limitacions. No es tracte doncs de conceptes excloents sinó que les cultures són el resultat d'aquesta 


\section{perifèria}

Número 16, junio 2012

revistes.uab.cat/periferia - www.periferia.name

articulació entre un universalisme present a tota la humanitat i un relativisme present a cada cultura.

Todorov (1988) admet la complexitat de les cultures, ja que creu que una cultura no es redueix a cap tret particular degut al fet que constitueix necessariament un conjunt de característiques. Tot i així, aquest fet no implica que es renunciï a un judici transcultural i que es declari que tot val. Per tant, no abandona l'ideal universalista. A part, estipula que uns dels objectius intrínsecs de les cultures és preservar la seva integritat on la seva naturalesa, a més, les confronta amb altres cultures diferents i estableix una constant adaptació a aquestes. Així, no existeix cap altra via per assolir la universalitat $i$ el coneixement universal que el diàleg entre cultures. Aquesta és la raó per la qual creu que l'etnocentrisme i el cientifisme són formes de pervertir I'universalisme.

Per la seva banda, Tambiah tampoc s'encasilla en cap dels dos marcs teòrics, ni l'universalisme ni el relativisme, per exposar la seva tesis. Tambiah (1990) creu en I'existència d'una unitat psíquica humana i en la universalitat de la racionalitat. Per contra, no creu en una superioritat de cap cultura i admet la diversitat cultural, la qual no resulta ser un dogma oposat a la universalitat psíquica de la humanitat. Opina que existeix una unitat d'alguns aspectes a nivell biològic, físic i mental i d'unes capacitats innates. Tot i aquest fet, degut al relativisme cultural, cada cultura respon de forma diferent $\mathrm{i}$ hi ha factors presents dins a cada cultura que superen aquesta unitat dins l'espècie humana.

\section{- El postmodernisme}

La postmodernitat, sorgida després de la segona guerra mundial, es manifesta amb la crítica de tota una època històrica on es substitueix la cultura per multicultura, a la universalitat i el monosentit per la pluralitat i el multisentit, una racionalitat única per una multiplicitat de racionalitats específiques, i com diria Foucault (1988), una veritat per una multitud de veritats. A més, segons Reynoso, la idea de modernidad se contrasta con la forma antigua, dominada por una idea naturalista y cíclica del curso de las cosas. Aquí está presente el concepto de superación que entiende al pensamiento como un desarrollo progresivo, donde lo nuevo es lo 


\section{perifèria}

Número 16, junio 2012

revistes.uab.cat/periferia - www.periferia.name

valioso. En cambio, en la posmodernidad las ideas de lo nuevo y de la superación no tienen vigencia. Lo posmoderno no sólo se caracteriza como novedad con respecto a lo moderno, sino también significa la desaparición de la categoría de lo nuevo y por lo tanto del fin de la historia como un proceso. En su lugar se revalidan diferentes historias y relatos que rescatan el carácter local y particular de la realidad (Reynoso 1998:15).

Foucault s'introdueix de ple en l'estudi del saber en termes de saber-poder, afirmant que en les societats democràtiques hi ha unes determinades relacions entre el saber $\mathrm{i}$ el poder que ens normalitzen, subjectant-nos a unes formes d'identitat concretes. El saber, per tant, no és mai neutre, sempre és poder, i separa entre els que compleixen les normes i els que no. Així doncs, amb la creació de la suposada societat de les llibertats i dels drets de I'home, van aparèixer un conjunt de micropoders que tenien la finalitat de fabricar un nou tipus d'individu, disciplinat i obedient, útil i adequat al nou sistema econòmic, polític i social (Vázquez 2005). Aquest punt el relaciono directament amb el que va propiciar I'agroindústria capitalista i la voluntat del poder mundial en "desenvolupar els països subdesenvolupats", amb el seu interès a l'hora d'assolir un alt guany econòmic i "fabricar" uns individus submisos en nom d'una ciència i una tecnologia "neutral". Per tant, hem passat de la macrofísica del poder sobirà present als estats, a una microfísica del poder disciplinari, la qual proporciona uns subjectes adaptats al sistema de forma discreta, aparentment innocent però alhora molt efectiva. A més, aquests micropoders arriben a crear els hàbits, costums i estils de vida, com el que proporciona el model capitalista i la seva vessant de I'agroindústria. Com diu Foucault:

Ese biopoder fue, a no dudarlo, un elemento indispensable en el desarrollo del capitalismo; éste no pudo afirmarse sino al precio de la inserción controlada de los cuerpos en el aparato de producción y mediante un ajuste de los fenómenos de población a los procesos económicos. (Foucault 1989:170).

Aquest fet es veu accentuat amb l'entrada del neoliberalisme potenciat per Thatcher i Reagan en el qual es té una concepció clarament constructivista i 


\section{perifèria}

Número 16, junio 2012

revistes.uab.cat/periferia - www.periferia.name

conductista segons la qual el mercat, els individus i la societat civil són realitats fabricades. Com anuncia Vázquez, "el individuo promovido por la gubernamentalidad neoliberal necesita ser fabricado. El interés en su propia realización personal, su capacidad de elección, sólo pueden brotar en un entorno adecuadamente programado" (Vázquez 2005:92). Per tant, es pot dir que s'han generat unes necessitats i una forma de produir aliments perfectament dissenyades perquè es vegi com a única forma útil i necessària un tipus de producció macrointensiva per assolir beneficis alimentaris, socials i econòmics. Així, es dissenya l'entorn que configura la subjectivitat dels individus on es crea la consciència de que per ser competitius en el mercat només és vàlida una sola forma de producció alimentària.

\section{Aplicació en el cas empíric}

Vistes diferents visions des de l'Antropologia social i cultural d'aquest debat mil-lenari, i també en temes d'alimentació, les teories exclusivament universalitses han quedat obsoletes, com també la idea d'un únic tipus de "progrés". Per tant, el concepte important des del que començar la crítica, és l'etnocentrisme. Així, estic d'acord amb Lévi-Strauss (1961) quan anuncia que cada societat porta a terme un tipus de "progrés relatiu" segons cadascuna d'elles i que, alhora, és necessària aquesta diversitat per obtenir un guany a nivell global, de la humanitat. Tanmateix, encara trobo més encertada la visió de Todorov (1988), el qual creu que la humanitat segueix un procés conjuntament però dins les diferències relatives de cada societat. Aquests autors em fan reafirmar la necessitat de potenciar la producció local diversificada, en favor precisament de les realitats locals i l'esdevenir global, enfront el "monocultiu" o la "monoproducció". Com Todorov (1988) i Castoriadis (1997), crec que la humanitat ha de seguir un camí i un objectiu comú, que en el cas plantejat, ha de ser el benestar i la llibertat personal amb el conseqüent assoliment dels productes alimentaris bàsics, I'autogestió d'aquests i tot dins la sostenibilitat del conjunt. Ara bé, tal i com diria Geertz, aquest no és pot basar en un tipus d'etnocentrisme, on es creu que I'agroindústria és el remei a tots els mals, ans el contrari, crec que és un dels grans aspectes que provoca els desequilibris socials i alimentaris que aquí senyalo. 


\section{perifèria}

Número 16, junio 2012

revistes.uab.cat/periferia - www.periferia.name

L'exemple d'Osona és molt representatiu dels efectes criticables d'un discurs agrouniversalista etnocentrat en el neoliberalisme. Fins als anys 80, la majoria de la població rural treballava en explotacions familiars on la diversitat agrícola-ramadera era molt present. És a dir, es tenia pocs animals per explotació però de diferents espècies (Garcia 2006:3), fet que provocava una major resiliència i millor adaptació al mediambient, una distribució propera al mercat local i a l'assoliment de I'autoconsum. Amb l'arribada de l'agroindústria i el mercat globalitzat, ajudat per la política agrària comunitària (PAC) provinent d'Europa, amb una protecció del mercat interior mitjançant barreres aranzelàries, es va intensificar la producció gràcies a la incorporació de noves tecnologies. Aquesta incorporació va anar de bracet amb el discurs de progrés i com a única solució per no perdre el mercat, guanyar beneficis i no quedar endarrerit. Aquesta visió i única forma de producció va donar bons resultats macro-econòmics principalment, ara bé, el mercat global va propiciar una major competència i l'obligació d'ampliar el nombre de caps de bestiar per obtenir més beneficis. Aquest fet, però, va provocar que es perdés una raça autòctona (porc vigatà), que tot i ser més rústica i adaptada al tipus d'alimentació present a la zona no produïa tant com altres races de porcs. Ara bé, aquestes últimes anaven acompanyades d'un tipus específic d'alimentació i d'unes condicions ambientals que implicaven un cost elevat en infraestructures. Tanmateix, es va accentuar la desvinculació de la ramaderia amb l'activitat agrària de la pròpia explotació, la dependència d'una alimentació externa regulada pels mercats internacionals de cereal, i una venda del producte final desvinculada del mercat local amb nul marge d'intervenció.

Així doncs, aquesta obligació ha anat creixent exponencialment, cosa que ha provocat que els pagesos es veiessin obligats a invertir en més instal-lacions, maquinària, genètica,... Tots aquests fets acompanyats per un augment de la contaminació de les aigües freàtiques degudes als purins i l'augment de l'ús de fertilitzants nitrogenats (Garcia 2006:3) i una desorgantizació de les xarxes socials presents en els mercats locals establertes anteriorment (Soldevila 2008). Respecte a la contaminació dels aqüífers pels purins, Osona és la comarca catalana amb més densitat de purí alliberada per hectàrea, $75^{\prime} 8 \mathrm{~m}^{3}$ per SAU ${ }^{11}$. Aquesta dada és el

${ }^{11}$ Superfície agrària utilitzable 


\section{perifèria}

Número 16, junio 2012

revistes.uab.cat/periferia - www.periferia.name

doble que la permesa per la ramaderia ecològica (Garcia 2006:5). Aquest fet té efectes directes amb la salut pública de la població d'Osona, ja que en aquesta comarca i degut a aquest fet es detecta el doble d'incidència de càncers gàstrics que la mitjana catalana i efectes potencialment negatius en nadons causant el "mal blau", un dèficit d'oxigenació de la sang ${ }^{12}$. A part, s'ha detectat també una alta presència d'antibiòtics com la sulfonamides en les aigües de la plana de Vic degut aquesta producció intensiva (García-Galán et al. 2009).

El punt actual és que els ramaders de porcí, degut al mercat, no han pogut assumir l'augment dels costos de producció degut a les necessitats específiques d'alimentació (el preu del pinso ha augmentat un $150 \%$ entre el 1990 i el 2011) ${ }^{13}$, instal-lacions ${ }^{14}$ i maneig que comporta aquesta producció intensiva. A més, com veurem, han perdut la capacitat de decisió per la comercialització. Aquest fet ha provocat que molts ramaders hagin deixat de ser propietaris dels animals i s'hagin integrat ${ }^{15}$ per almenys amortitzar les instal-lacions. Al 2003 i a la província de Barcelona, el $73 \%$ de les explotacions d'engreix de porcí ja eren amb integració (Soldevila 2008:61).

Així, el control actual de la producció i comercialització dels porcs de la plana de Vic està en mans de molt poques empreses. Els escorxadors, que a Osona són tots privats, hi juguen un paper clau i ja són els que dominen la comercialització i en molts casos el preu a pagar al productor, ja que aquest els hi ven el porc degut a la desvinculació i la manca de control respecte a la distribució i comercialització. Entre les vuit empreses que exporten més carn de porc a nivell de l'Estat Espanyol, hi ha quatre empreses ${ }^{16}$ propietàries d'algun dels escorxadors d'Osona. A més, aquestes

\footnotetext{
12 www.vic.cat Auditoria ambiental

${ }^{13}$ Dossier informatiu JARC. Setmana 46/2011

14 L'alimentació representa un $62 \%$ dels costos totals de producció. Les instal·lacions un 16'6\%.(Soldevila 2008:105).

15 Un productor integrat significa que el ramader posa les seves instal-lacions i la feina per cuidar un bestiar que no és de la seva propietat, és a dir, rep un sou fix per cuidar el bestiar d'un altre ramader o empresari.

16 Càrniques Toni-Josep, Càrniques Solà, Patel S.A. i RIVASAM Vic. (Revista Alimarket, 2006, dins Soldevila 2008:40)
} 


\section{perifèria}

Número 16, junio 2012

revistes.uab.cat/periferia - www.periferia.name

empreses, juntament amb les d'elaborats carnics ${ }^{17}$, són les que tenen més nombre de caps de bestiar en propietat, sovint tenen fàbriques de pinso en propietat $i$, per tant, el major volum de comercialització. Al 2010, el 70\% del producte final d'aquests escorxadors, d'uns 25.000 porcs diaris, s'exportava a la Unió Europea, Rússia o Xina ${ }^{18}$.

\section{Conclusió}

Seguint el tema de la creació de la subjectivitat pel model neoliberal de Foucault, s'ha arribat, a crear un "treballador content" a partir del biopoder (Foucault 1989:170). Aquest, exemplificat amb el productor de porcs integrat, és a dir el que predomina avui dia a la plana de Vic, el qual està supeditat a un empresari de gran escala, fa seus els objectius de l'empresa i els interessos del capitalisme global tot desenvolupant una rutina laboral, un conformisme i un agraïment pel sol fet de poder treballar. Per exemple, una expressió usada en aquestes contrades que representa un ideal sense impossibilitat de canvi és: "de porc i de senyor se n'ha de venir de mena". Es forma, per tant, individus dependents i amb una subjectivitat alienada, fet que provoca una major rendibilitat de les grans multinacionals. Aquestes, essent les mateixes que les indústries químiques, farmacèutiques o de llavors, estableixen el control mundial de la carn de porc degut al fet que l'aliment produït per l'alimentació d'aquests porcs ha d'estar compost per unes varietats especifiques de blat, ordi o blat de moro casi sempre transgènic, on s'ha usat pesticides i s'ha aplicat un gran nombre de medicaments al-lopàtics als porcs. Així, la transnacional Cargill és la principal empresa del sector pinso a nivell Espanyol i la seva ubicació es troba a Catalunya (Soldevila 2008:38).

Amb aquestes dades presentades, no puc que estar més d'acord amb la següent afirmació: El desenvolupament de la ramaderia intensiva no és fruit del desenvolupament i "evolució" de l'explotació agrícola sinó que ve motivat pels interessos de la indústria agroalimentària (Garcia Pascual 1993, dins Soldevila 2008:24).

\footnotetext{
17 Casa Terradelles S.A. i Embutis Monells S.A., representen a l'Estat Espanyol la tercera i sisena empreses, segons nivell de producció. (Revista Alimarket, 2006, dins Soldevila 2008:40)

${ }^{18}$ www.osonacomarca.com 03 juny 2010
} 


\section{perifèria}

Número 16, junio 2012

revistes.uab.cat/periferia - www.periferia.name

En el present text, s'ha intentat demostrar com un universalisme fortament lligat a l'etnocentrisme occidental de base neoliberal pot desestructurar i fer perdre l'autonomia de les societats locals tot creant uns desequilibris cada cop més marcats i una falta cada cop més accentuada de llibertat d'elecció personal. Tanmateix, com diria el mateix Foucault, on s'exerceix un poder concret sempre hi ha possibilitat de resistència. Aquesta seria, en el cas presentat, una forma de producció d'aliments lligada al context social i ecològic dins l'àmbit local. De fet, el poder no elimina la llibertat, sinó que aquesta n'és la condició de possibilitat. I de la mateixa manera que no hi ha un únic poder, no hi ha una única resistència, ni el poder és exclusiu d'una classe dominant ni la resistència ho és d'una classe dominada, sinó que tant I'un com l'altra, com tot element entremig, estan estesos com una xarxa que travessa la societat. Per tant, es pot dir que el poder articulat dins l'agroindústria no només ha tingut aspectes negatius, sinó també efectes creatius, en el sentit que anomenava Todorov i que ha conscienciat, impulsat, ampliat i incitat una nova forma de producció d'aliments dins el món globalitzat com el que es proposa en la sobirania alimentària, el proposat pels conceptes de decreixement o el consum de proximitat de productes $\mathrm{Km}$ 0. Així, com també defensava Foucault, si volem canviar I'horitzó necessitem transformar la identitat de I'home contemporani creant noves formes de subjectivitat que ens allunyin de ser consumidors endormiscats i obedients que ens deixem portar, tal i com anomena Nietzsche, per "I'esperit de ramat" que configura el neoliberalisme.

Cal tenir en compte que la meva postura no és de negació simplista contra la globalització, ni es renega de tota millora tecnològica, ja que reconeixo que són aspectes que comporten alhora certs beneficis i certs inconvenients. Per exemple, crec que I'assoliment de certes millores a I'hora d'obtenció d'aliments adquirides per una societat gràcies a la globalització es podran transferir millor aquests coneixements en altres societats, les quals podran valorar la seva conveniència a I'hora d'aplicar-los, sempre tenint en compte les diferències culturals, socials, econòmiques i ecològiques presents. Aquest és precisament el problema que mencionava Todorov (1988) sobre el fet que les innovacions venen en "packs" i moltes vegades no podem separar aspectes com el simbòlic, el moral, el socioorganitzatiu o el tecnològic. Per tant, no proclamo un relativisme extrem que 


\section{perifèria}

Número 16, junio 2012

revistes.uab.cat/periferia - www.periferia.name

impossibiliti l'intercanvi i comunicació entre les diferents formes de produir aliments. Més bé proposo un consum responsable, una forma de producció local que estigui relacionada i amb comunicació amb altres formes de produir, però que alhora tingui el poder necessari per usar i establir la més adient depenent de les seves necessitats socials establertes pels propis individus allunyats i desenganxats de l'esperit capitalista i neoliberal generador de desigualtats. Per tant, estic totalment en contra és en el fet d'imposar ja sigui de forma directe o de forma indirecte, mitjançant discursos en nom de la ciència, el progrés, el desenvolupament o la productivitat, un tipus determinat de producció única i veritable, quan el que hi ha darrera és un interès econòmic de grans lobbies.

M’agradaria acabar el treball amb una cita de Pastor i Ovejero:

Ciertamente, no se trata de una cuestión sencilla (...). La libertad (...) es un camino salvaje y cruel. Un camino que es, además, interminable, infinito. Porque la libertad completa es imposible. La libertad es un horizonte inapresable. $Y$ es que, como dice Foucault, "el martillo que rompe una cadena es una nueva cadena que será preciso romper". Así se avanza por el camino hacia la libertad: rompiendo cadenas con martillos que se convierten en cadenas. Así una y otra vez. Pero no deberíamos olvidar que con cada paso que damos ganamos un "grado de libertad". (Pastor i Ovejero 2007:109).

Si volem guanyar graus de llibertat, també en l'àmbit de l'alimentació i de la producció agropecuària, hem de seguir trencant cadenes, reflexionant, transformant i "problemitzant" el que ens envolta. No podem donar les coses per suposades i acomodar-nos. Fer Teoria Crítica del Pensament Antropològic no consisteix en trobar una teoria explicativa definitiva, sinó mantenir sempre la curiositat i el dubte, tenir inquietuds que mai no acabarem de satisfer, trobar noves preguntes immediatament després de respondre les anteriors, obrir noves perspectives que no s'havien tingut en compte i, en resum, explorar contínuament. Així doncs, podem usar la Teoria Crítica per posar en dubte certes aspectes fonamentals de les societats occidentals, suposadament democràtiques, per lluitar contra el pensament únic del neoliberalisme, per transformar un món injust i 


\section{perifèria}

Número 16, junio 2012

revistes.uab.cat/periferia - www.periferia.name

desigual que, encara que a vegades la desesperança ens porti a pensar el contrari, té alternatives. Un primer pas és I'alimentació, un recurs bàsic per tota la humanitat que tot $\mathrm{i}$ que es produeix en quantitats suficients per cobrir les necessitats mundials, o fins i tot molt més enllà, paradoxalment està repartit de forma desigual, causant malnutrició i fam degut el fet d'estar subjecte a I'especulació econòmica. Així, un cop assolida la sobirania alimentària, amb dret a la terra i un repartiment equitatiu dels aliments produïts, continuarem la Teoria Crítica per continuar sempre intentant millorar les distintes situacions, ja que conformar-nos seria una actitud molt poc adient per la nostra disciplina.

\section{Bibliografia}

Balanyá, B, et al. (2002). Europa S.A.: la influencia de las multinacionales en la construcción de la UE. Barcelona: Icaria.

Castoriaris, C. (1997). "The retreat from autonomy: Postmodernism as Generalized Conformism", "The State of the Subject Today", World in Fragments, Stanford University Press, pp. 37-43, 137-171.

Duch, Gustavo (2010). Lo que hay que tragar. Minienciclopedia de política y alimentación. Barcelona: Libros del lince.

Duch, Gustavo (2010). Un mundo sin transnacionales. Diario Público. 17 Abril 2010.

Ellen, R. F. (2007). Modern crises and traditional strategies: local ecological knowledge in island Southeast Asia. Oxford: Berghahn.

Lombard, Jacques (2005 [1994]). Introducción a la etnología. Madrid: Alianza Editorial.

Moore, Fances., Collins, Joseph., Rosset, Peter., Esparza, Luis., (2005). Doce Mitos sobre el hambre, un enfoque esperanzador para la agricultura y la alimentación del siglo XXI. Barcelona: Icaria editorial, 


\section{revista de recerca i formació en antropologia}

\section{perifèria}

Número 16, junio 2012

revistes.uab.cat/periferia - www.periferia.name

Foucault, Michael (1988). Las palabras y las cosas. Madrid: Siglo XIX.

Foucault, Michael (1989). Historia de la sexualidad I. La voluntad de saber. Madrid: Siglo XXI.

Garcia, Ferran (2006). Impacte del canvi climàtic sobre la ramaderia a la comarca d'Osona. Barcelona: Veterinaris sense fronteres.

García-Galán, Ma Jesús., Garrido, Teresa., Fraile, Josep., Ginebreda, Antoni., DíazCruz, Sílvia., Barceló, Damià. (2009). Simultaneous occurrence of nitrates and sulfonamide antibiotics in two ground water bodies of Catalonia. Journal Hydrology. Volume 383, Issues 1-2, Pages 93-101 (15 March 2010).

Geertz, Clifford (1996). "Anti-antirrelativismo" a Los usos de la diversidad, Barcelona: Paidós, pp. 93-124.

Gellner, Ernest (1982). "Relativism and universals", M. Hallis, S. Luckes (eds.), Rationality and Relativism. Oxford/Cambridge: Blackwell

Gellner, Ernest (1983). Naciones y Nacionalismo. Oxford: Basil and Blackwell Plublishers.

Gellner, Ernest (1992). Posmodernismo, razón y religión. Barcelona: Paidós, 1994.

Gimeno, J. C., Monreal, P. (1999). La controversia del desarrollo. Críticas desde la antropología. Madrid: Los libros la Catarata.

Habermas, Jürgen (1999). Aclaraciones a la ética del discurso. Madrid: Trotta, D, L, (2000)

Harris, Marvin (2008 [1968]). El desarrollo de la teoría antropologica. Una historia de las teorías de la cultura. Madrid: Siglo XXI. 


\section{perifèria}

Número 16, junio 2012

revistes.uab.cat/periferia - www.periferia.name

Lévi-Strauss, Claude (1985 [1962]). "La ciència del concret" dins El pensament salvatge. Barcelona: Edicions 62, pp. 43-76.

Lévi-Strauss, Claude (1961). Raza y cultura, Barcelona: Càtedra. 1996.

Martínez, F. (2002). La globalización en la agricultura: las negociaciones internacionales en torno al germoplasma agrícola. México, D.F.: Plaza y Valdés,

Metcalf, B. D. (2003). Historia de la India. Cambridge: Cambridge University Press,

Reynoso, Carlos (1998). El surgimiento de la antropología posmoderna. Barcelona: Ed. Gedisa.

Pastor, Juan i Ovejero, Anastasio (2007). Michael Foucault, caja de herramientas contra la dominación. Oviedo: Universidad Oviedo.

Reboul, O. (1973). Nietzsche, crítico de Kant. Barcelona: Editorial Anthropos. (1993).

Soldevila, M. Victòria (2009). Les repercussions de la Directiva Nitrats sobre la filière porcina a Catalunya. Generalitat de Catalunya: Tallers Gràfics Hostench, S.A.

Stolcke, Verena (1993). "De padres, filiaciones y malas memoria. Qué historias de qué antropologías?" J. Bestard i Camps (coord.), Después de Malinowski. Sta Cruz de Tenerife: Asociación Canaria de Antropología, pp. 147-198.

Tambiah, Stanley Jeyaraja (1990). "Rationality, relativism, the translation and commensurability of cultures", Magic, Science, Religion, and the Scope of Rationality, Cambridge: Cambridge University Press, pp. 111-139.

Todorov, Tzvetan (1988). "Le project universaliste", Anthropologie et Sociétés, vol 12, no 1, pp.5-11 (Traducció de Verena Stolcke, novembre 1997). 


\section{perifèria}

Número 16, junio 2012

revistes.uab.cat/periferia - www.periferia.name

Vázquez, Francisco (2005). "Empresarios de nosotros mismos. Biopolítica, mercado y soberanía en la gubernamentalidad neoliberal" dins Ugarte, J (comp.) (2005). La administración de la vida. Estudios biopolíticos. Barcelona: Anthropos, pp. 73-103. 